\title{
Resolution Enhanced of GRBR Observation-Based Ionospheric Tomography in Indonesia
}

\author{
Timbul Manik $^{1 *}$, Adi Purwono ${ }^{1}$, Musthofa Lathif $^{1}$, Mario Batubara $^{1}$, Mamoru Yamamoto $^{2}$ \\ ${ }^{1}$ Space Science Center, National Institute of Aeronautics and Space (LAPAN) Indonesia \\ Jl. Dr. Djundjunan No. 133, Bandung 40173, Indonesia. Tel. +62-22-6012602, Fax. +62-22-6014998 \\ ${ }^{2}$ Research Institute for Sustainable Humanosphere (RISH), Kyoto University, Japan \\ "Email: timbul.manik@lapan.go.id
}

\begin{abstract}
An ionospheric tomography reconstruction using Algebraic Reconstruction Technique (ART) method has been successfully carried out recently. Data utilized on this work was a campaign-based Gnu-Radio Beacon Receiver (GRBR) observation in West Java during 8-10 November 2016 and 25-29 September 2017 data. Grid resolution of the tomography previously had been increased in the in the latitudinal ( $0.5 \mathrm{o}$ horizontal direction) and altitude $(\sim 25 \mathrm{~km}$ in vertical direction) scales. Although the quality of the tomography has also met a compatibility level through the correlation analysis (e.g. 85\% of correlation coefficient), the computation result should be improved in order to get the best value of bias frequency (i.e. $<1 \mathrm{MHz}$ ). Through this opportunity, the result of the tomography within the grid resolution of $0.5 \mathrm{o}$ and $\sim 25 \mathrm{~km}$ for the latitude and altitude respectively is presented.
\end{abstract}

Keywords: ART, GRBR observation, grid resolution, ionospheric tomography

Abbreviations: GRBR (Gnu-Radio Beacon Receiver), IRI (International Reference Ionosphere), LEO (Low-Earth Orbit), ART (Algebraic Reconstruction Technique), TEC (Total Electron Content).

\section{INTRODUCTION}

The ionospheric tomography techniques is proposed to overcome observation to an area along remote region that could not be excluded by the instrument coverage. The ionospheric tomography techniques results a map of variety of spatial distribution of the ionosphere in space both latitude and longitude by using data obtained from the beacon satellite receiver system.

A beacon satellite receiver system to measure the TEC in the ionosphere layer called the GNU Radio Beacon Receiver (GRBR) has built in several time ago (Yamamoto, 2008) and has been developed to be a GRBR observation network of in Indonesia (Manik and Lathif, 2011). This measurement system produces some trajectory parameters of the LEO satellite trajectory, some amount of the received satellite signal powers, the relative TEC and S4 (scintillation). The use of data received from GRBR system can be developed for further study as the characteristics distribution of electron density in the ionosphere in the twodimensional spatial space.

A campaign-based Gnu-Radio Beacon Receiver (GRBR) observation has been conducted previously in West Java during 8-10 November 2016 and 25-29 September 2017. (Manik, 2017). Data from this observation is utilized for ionospherci tomography reconstruction using Algebraic Reconstruction Technique (ART) methode. Grid resolution of the tomography on previous work was 0.50 in horizontal direction and $50 \mathrm{~km}$ in vertical direction. The quality of the tomography was good and met a compatibility level through correlation coefficient of 0.8665 and bias frequency 1.6903 MHz (Manik et al., 2018). In this work, grid resolution of the tomography is increased to be 0.5 o horizontal direction (latitudinal) and $~ 25 \mathrm{~km}$ in vertical direction (altitude) scales in order to get a good compatibility level through of correlation coefficient when compare to ionosonde observation, and also get the best value bias frequency.

\section{MATERIALS AND METHODS}

\section{Observation and Data}

A campaign GRBR ionospheric observation was conducted on 8-10 November 2016 and on 25-29 September 2017 in West Java as shown in Figure 1. Three sets GRBR receiver were placed in three locations, in Indramayu (INDR: $6,35^{\circ} \mathrm{S}, 108,33^{\circ} \mathrm{E}$ ), in Sumedang (TJS: $6,91^{\circ} \mathrm{S}, 107,83^{\circ} \mathrm{E}$ ), and in Pameungpeuk (PMPK: $7.63^{\circ} \mathrm{S}, 107.69^{\circ} \mathrm{E}$ ). Distance between the INDR-TJS was estimated to be around 62 $\mathrm{km}$, and the TJS-PMPK was around $80 \mathrm{~km}$. Times for tbservation in three locations are adjusted to follow time on the global internet network, so there is no time difference when the satellite passes over the location.

The satellite passing schedule was based on TwoLine Elements (TLE) data which obtained when observing from the site http: //www.rish. kyotou.ac.jp/digitalbeacon/sub2.html. During the observation, three receivers in these three locations receive dual frequency of 150 and $400 \mathrm{MHz}$ signals from low orbit satellites (LEO) that passed over Indonesia, including COSMOS2407, COSMOS2463, and DMFPS15. The height of the COSMOS satellite 
ranges from 1000-1100 km, while the DMSPF15 satellite is around $850 \mathrm{~km}$. (Manik et al., 2018).

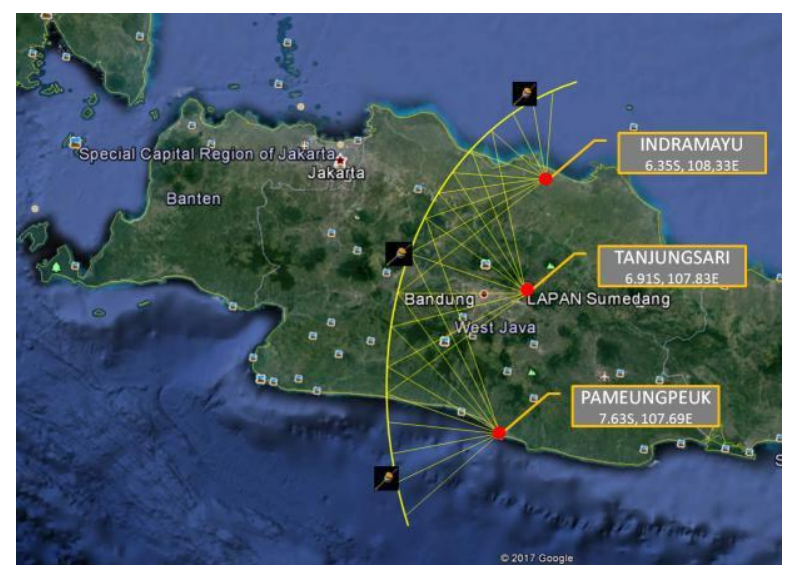

Figure 1. Location of campaign-based observation in West Java (Manik et al, 2017).

\section{Methods}

GRBR obervation utilizing Doppler frequency differences between two frequencies emitted by LEO satellites in determine ionospheric absolut TEC value. Basic data for computation of tomography can be expressed as follows:

$$
Y=A x+E
$$

$\mathrm{Y}$ is TEC data from observation, $\mathrm{x}$ is unknown electron density parameter, A is matrix of geometry, and $\mathrm{E}$ is discretization error (Thampi et al., 2007, Manik et al., 2017). Reconstruction of ionospheric electron density can be done by using TEC from this observation. (Leitinger et al., 1975, Austen et al., 1986, Austen et al., 1988, Thampi et al., 2007, Thampi and Yamamoto, 2010, Vierinen et al., 2014).

ART method is a method of reconstruction using an iterative calculation process to solve problems in a linear multi-equation. The processing in ART consists of initialization matrix construction, calculation of correction factors, reconstruction process, then calculation of convergence results. At the end of the process, the output of this technique is a numerical approach that can be calculated by the following equation (Batubara et al., 2016, Manik et al., 2018):

$$
f_{j}^{k+1}=f_{j}^{k}+\propto \frac{p_{i}-\sum_{n=1}^{N} A_{i n} f_{n}^{k}}{\sum_{n=1}^{N} A_{i n}^{2}} A_{i j}
$$

$f_{j}^{k}$ is obtained from global IRI2012 model, $\propto$ is relaxation parameter, pi is observation data, A matrix of geometry, and $\mathrm{f}$ is electron density value $(\mathrm{Ne})$. The value of the parameter $f_{j}^{k+1}$ can be obtained when it reaches the convergence conditions at iteration $\mathrm{k}+1$.

The TEC value obtained from tomography can be correlated with the critical frequency value of the F / F2 layer (foF2), assuming that the ionosphere has a vertically homogeneous density, and the electron density of $\mathrm{Ne}$ is equal to the maximum electron density of the F2 layer $(\mathrm{NmF} 2)$. The relation between the maximum electron density of ionospheric F2 layer $(\mathrm{NmF} 2)$ and the critical frequency of $\mathrm{F} 2$ layer is expressed as follows:

$$
f o F 2=\sqrt{\frac{N m F 2}{1.24 \times 10^{-6}}}
$$

foF2 in $\mathrm{MHz}$, and $\mathrm{NmF} 2$ value in electron/m3.

In increasing resolution of the tomographic, the space to be reconstructed is divided into grids with a 25 $\mathrm{km}$ vertical resolution from 100 to $1000 \mathrm{~km}$, and $0.5^{\circ}$ in latitude or horizontally from $9^{\circ} \mathrm{S}$ to $8.5^{\circ} \mathrm{N}$. Expected output is an imaging of the electron density distribution along the location above the West Java region. Validation of the ionospheric tomography results are carried out by comparing the parameters of the critical frequency foF2 and the maximum electron density value of $\mathrm{NmF} 2$ from the ionosonde observation.

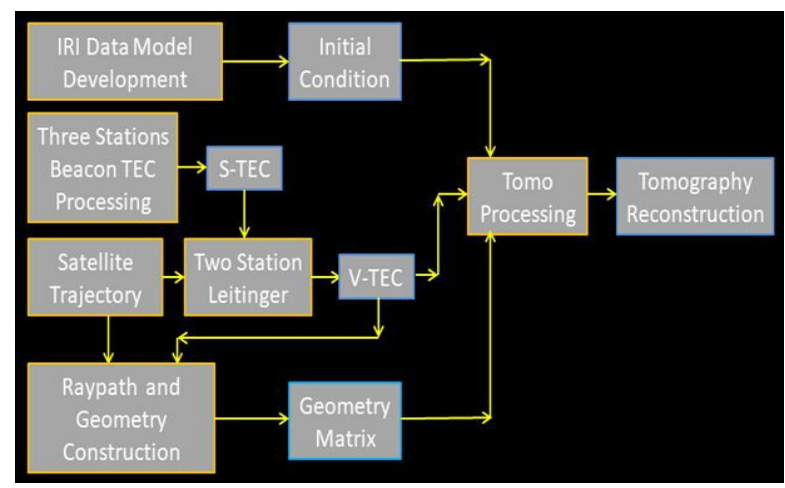

Figure 2. Data processing chart (Manik et al, 2018).

In this work, data processing for tomographic reconstruction is carried out following the chart as shown below in Figure 2. The processing is describe as follows. The IRI-2012 ionospheric IRI global model was used as the initiation of the ionospheric TEC. Then relative TEC (S-TEC) from GRBR observation is corrected by two station correction techniques from Leitinger (Leitinger et al., 1975). Satellite trajectory data and S-TEC corrections are used to calculate the absolute value of TEC (V-TEC). On the other hand, the tomographic matrix of geometry is generated before ART procedures. This matrix can be generated by construct the ray path data from satellite ray path. The ray path data obtained from the calculation of trigonometric spatial in two dimension based on the satellite trajectory data. Finally, TEC background initiation data from IRI-2012, absolute TEC data, and geometry matrix from satellite trajectories are used in the tomography process to obtain tomographic matrix as a result of ionospheric tomography reconstruction. 


\section{RESULTS AND DISCUSSION}

From phase difference analysis between two signals of $150 \mathrm{MHz}$ and $400 \mathrm{MHz}$ received by GRBR at each location, a relative TEC value or S-TEC is obtained. The lowest relative TEC value assumed to be zero is the TEC value at the closest distance between the satellite and the receiver at each location. Relative TEC values (S-TEC) are then converted to absolute TEC values (V-TEC) using the two-station method developed by Leitinger (Leitinger et al., 1975), which is then used for reconstruction of ionospheric tomography. Figure 3 and Figure 4. show profiles of relative TEC values (Slant-TEC) and the absolute TEC value obtained for observations in 2016 and 2017 respectively (Manik et al., 2018).
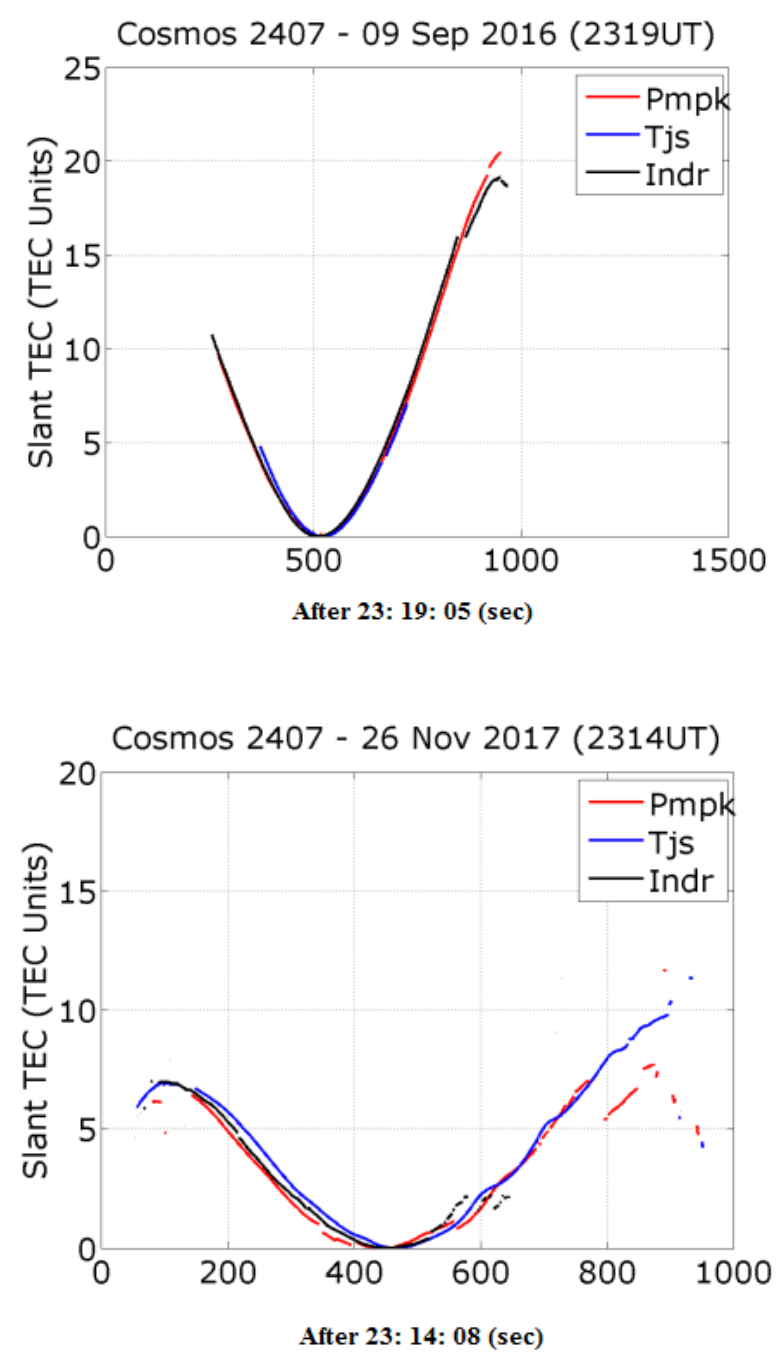

Figure 3. Relative TEC (S-TEC) obtained from the observation.

Tomograms resulting from tomographic reconstruction of ionospheric electron density from previous work are shown in Figure 5. The vertical axis is the altitude of the ionosphere in kilometers $(\mathrm{km})$, and the horizontal axis is the position of the geographical latitude.
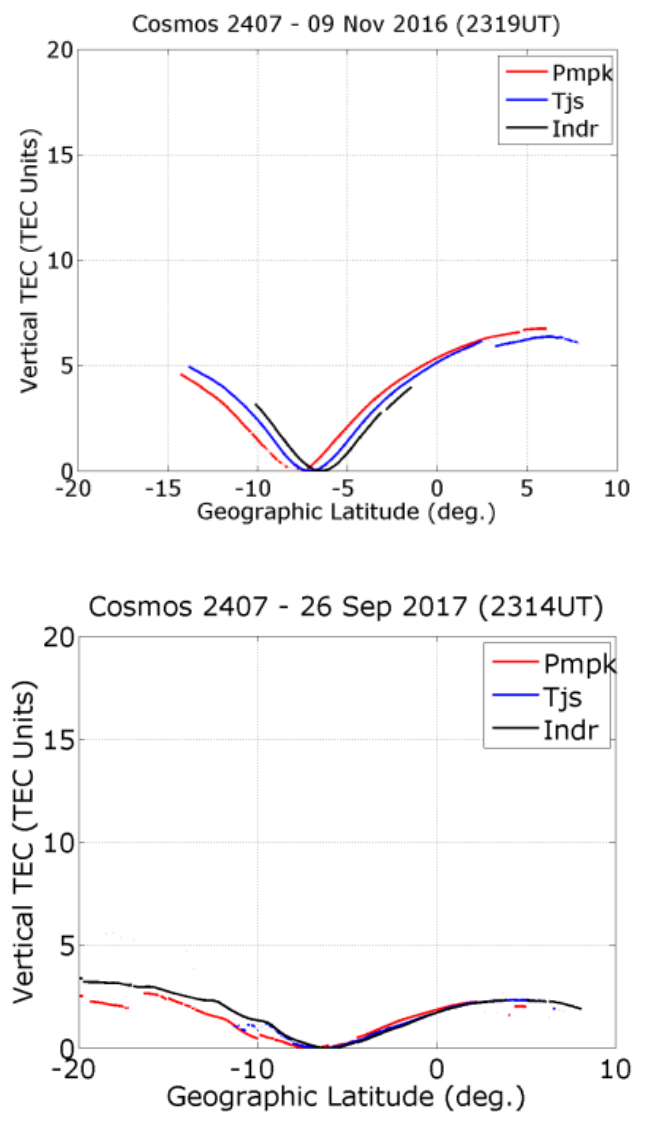

Figure 4. Absolute TEC (V-TEC) obtained conversion from S-TEC by Leitinger two station method.
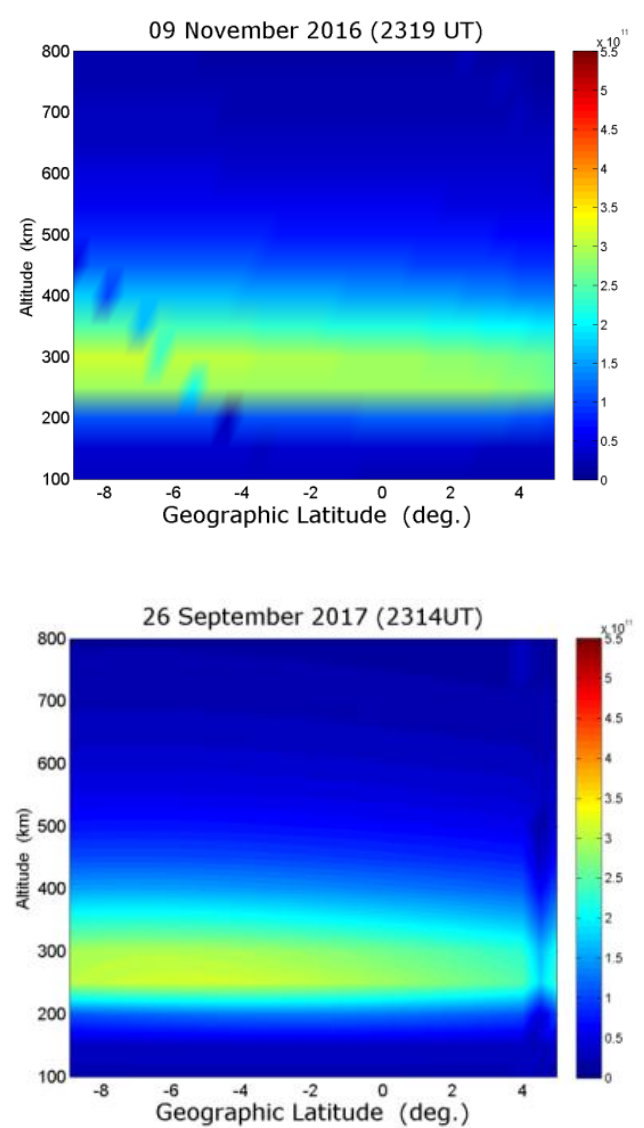

Figure 5. Result of tomography base on data of 2016 and 2017 from previous work. 
The results of ionospheric tomography reconstruction from previous work provided an overview of the ionospheric vertical distribution over West Java along the longitude of $108^{\circ} \mathrm{E}$. In general, it can be seen the range of electron density values at night between $0.5-2 \times 1011$ electrons $/ \mathrm{m}^{3}$, in the range $2-4 \times$ 1011 electrons/m3 during the midday, and in the range of 2.5-5.5x1011 electrons $/ \mathrm{m} 3$ and more during the day.

When the tomography results taking a comparison with foF2 value from ionosonde observation, the quality of the tomography was good and met a compatibility level through correlation coefficient of 0,8665 and bias frequency $1,6903 \mathrm{MHz}$. as in shown Figure 6. (left). For a comparison between the maximum electron density value of $\mathrm{NmF} 2$ of the tomography and of taken from ionosonde, the regression equation of $y=0.3013 x+(1 x$ 1011) was obtained with the correlation coefficient obtained is 0.8529 as shown in Figure 6. (right) (Manik et al., 2018).
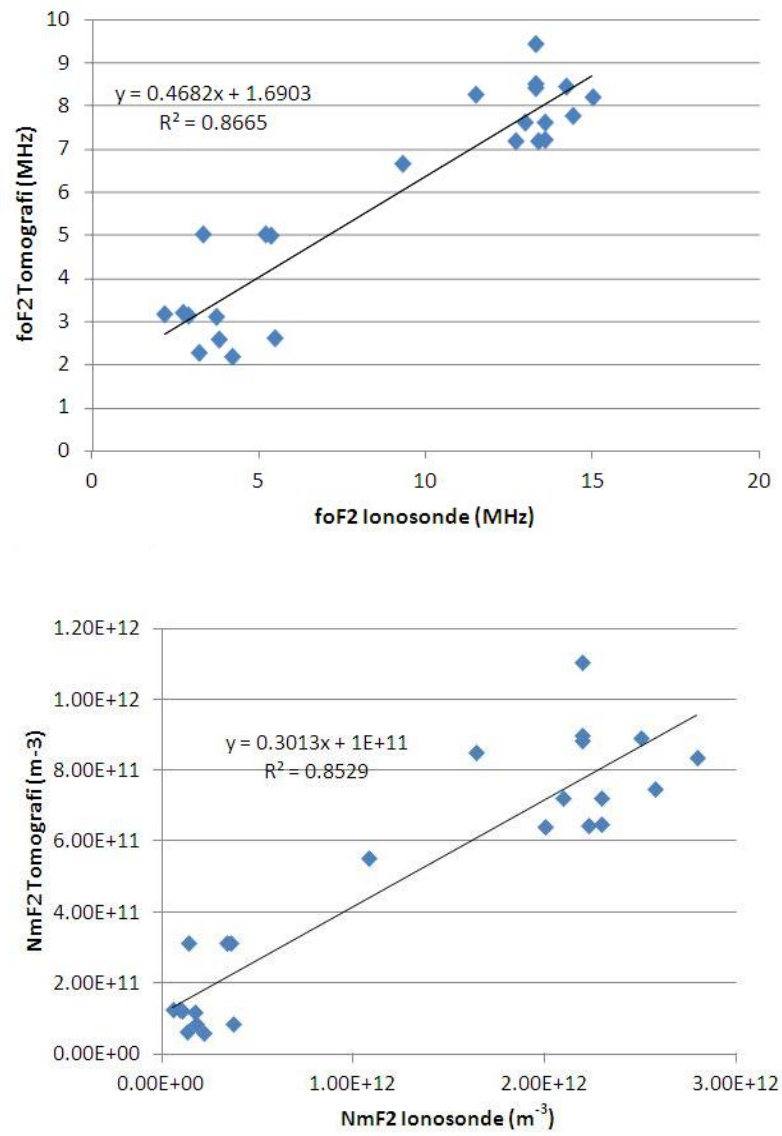

Figure 6. Comparison with the ionosonde observation, foF 2 (left) and $\mathrm{NmF} 2$ (right).

In order to better ionospheric tomography, grid resolution of the tomography is increased. In the computation of the tomography, particularly when generating matrix of geometry which is calculated before ART procedure.
The grid resolution of the computation is increase to be 0.50 horizontal direction (latitudinal) and $\sim 25 \mathrm{~km}$ in vertical direction (altitude) scales. By this enhancement, a good compatibility level through of correlation coefficient when compare to ionosonde observation and the best value bias frequency are hopefully will achieved.

In the first step, as also has been conducted in the previous work, the International Reference Ionosphere (IRI) 2012 global model as the initiation of the ionosphere condition is taken. The previous site was http://omniweb.gsfc.nasa.gov/vitmo/iri2012_vitmo.htm 1, while in this work, the source has been shifted to the new site https://ccmc.gsfc.nasa.gov/cgi-bin/modelweb/models/vitmo_model.cgi (Compston, 2018), managed by Comminut Coordinated Modeling Center (CCMC). Some changes have been conducted when taking the output of the IRI2012 model from this site. Output of the IRI-2012 global model are shown in Figure 7. The vertical axis is the altitude in kilometers $(\mathrm{km})$, and the horizontal axis is the position of the geographical latitude, while the right bar is electron density in electrons/m3.
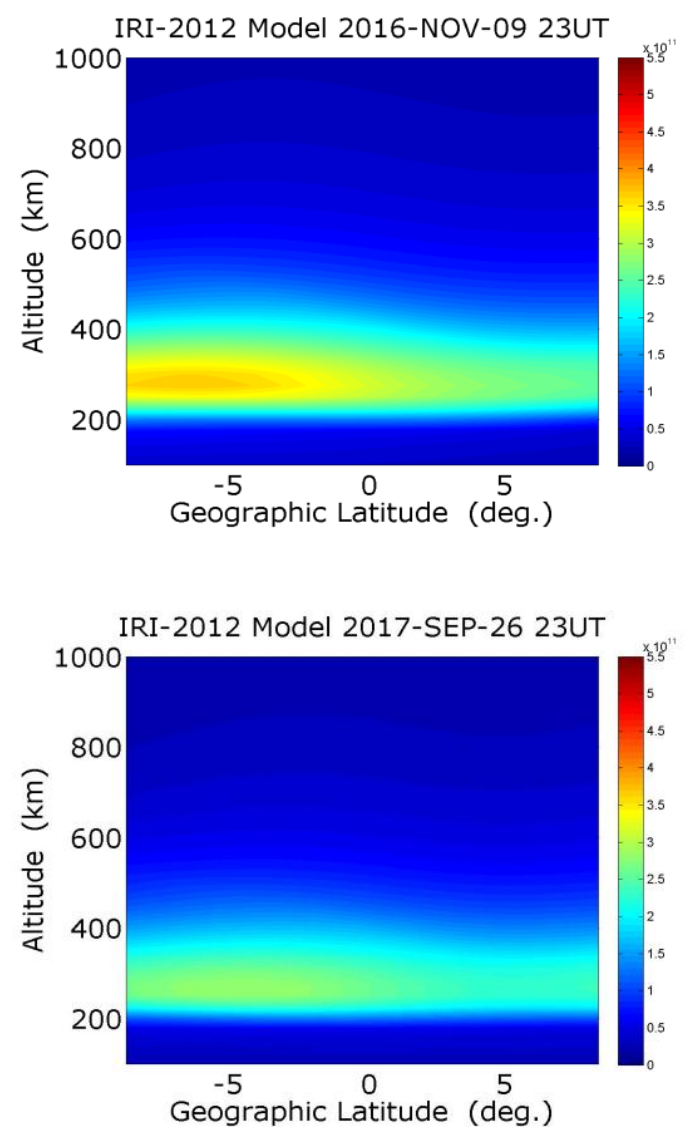

Figure 7. Output of IRI-2012 model, for 09 November 2016 and 26 September 2017.

Following the procedure of tomography as mentioned on the previous work, the computation of the tomography is again carried out. Matrix of geometry is generated by construct the ray path data 
from satellite ray path with the enhanced grid resolution. Due to large matrix of geometry which is double of the previous work, the computation process is much longer.

Base on this initiation condition of the ionosphere, ad following the ART procedure as mentioned on Data processing chart on Figure 2, the tomograhy reconstruction of the electron density with the enhancement resolution is conducted. The tomograms of the tomography taken from 2016 and 2017 data are shown in Figure8.The vertical axis is the altitude of the ionosphere in kilometers $(\mathrm{km})$, the horizontal axis is the position of the geographical latitude, and the right color bar is electron density in electrons $/ \mathrm{m}^{3}$.
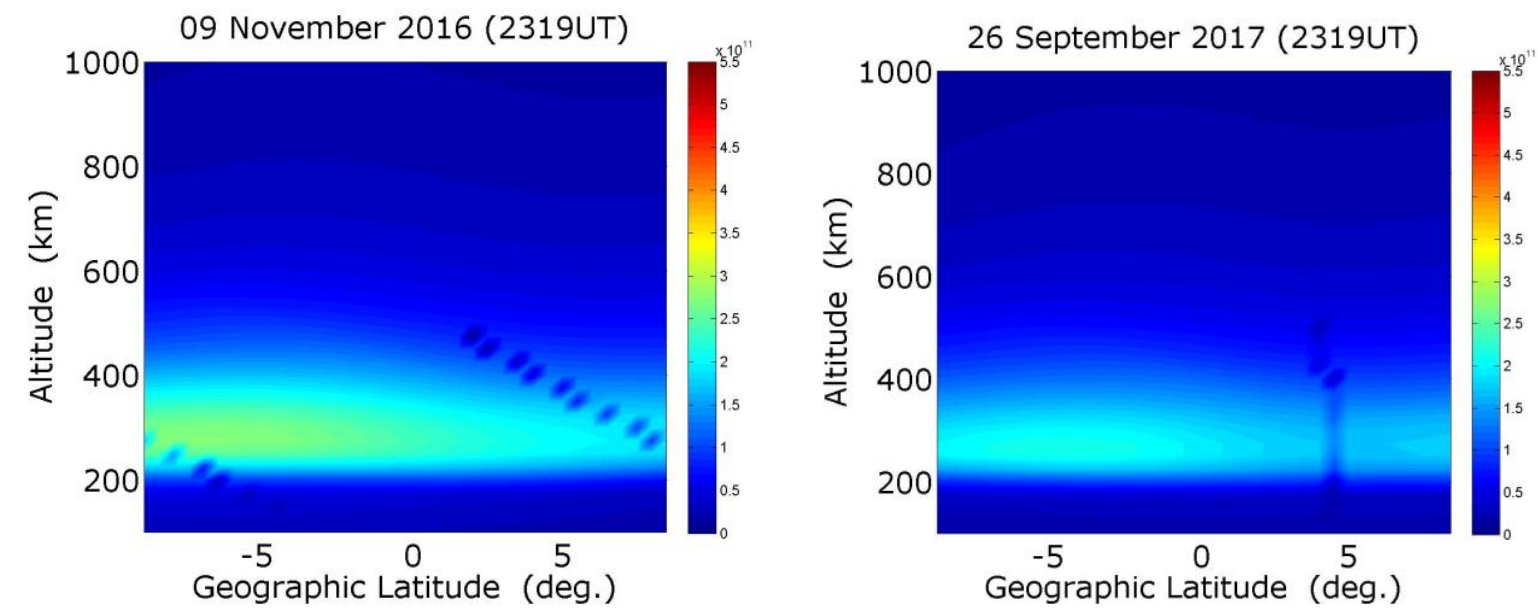

Figure 8. Results of tomography reconstruction taken from data of 2016 and 2017.

Table 1. Comparison of tomography result with ionosoonde observation.

\begin{tabular}{|c|c|c|c|c|c|c|}
\hline \multirow[t]{2}{*}{ No. } & \multirow[t]{2}{*}{ Date } & \multirow[t]{2}{*}{ Time } & \multicolumn{2}{|c|}{ Tomography } & \multicolumn{2}{|c|}{ Ionosonda Obs. } \\
\hline & & & NmF2 & foF 2 & foF2 & NmF2 \\
\hline 1 & 9-Nov-2016 & $12 \mathrm{UT}$ & $8.82 \mathrm{E}+11$ & 8.433086 & 9.33 & $1.08 \mathrm{E}+12$ \\
\hline 2 & & $23 \mathrm{UT}$ & $2.76 \mathrm{E}+11$ & 4.717012 & 5.38 & $3.59 \mathrm{E}+11$ \\
\hline 3 & 10-Nov-2016 & $07 \mathrm{UT}$ & $1.29 \mathrm{E}+12$ & 10.20347 & 13.3 & $2.19 \mathrm{E}+12$ \\
\hline 5 & & $23 \mathrm{UT}$ & $2.75 \mathrm{E}+11$ & 4.706807 & 3.34 & $1.38 \mathrm{E}+11$ \\
\hline 6 & 25-Sep-2017 & $19 \mathrm{UT}$ & $8.38 \mathrm{E}+10$ & 2.600287 & 3.81 & $1.80 \mathrm{E}+11$ \\
\hline 7 & & $22 \mathrm{UT}$ & $1.99 \mathrm{E}+11$ & 4.005407 & 3.71 & $1.71 \mathrm{E}+11$ \\
\hline 8 & 26-Sep-2017 & $09 \mathrm{UT}$ & $9.62 \mathrm{E}+11$ & 8.806729 & 13.6 & $2.29 \mathrm{E}+12$ \\
\hline 9 & & $10 \mathrm{UT}$ & $9.13 \mathrm{E}+11$ & 8.579561 & 13 & $2.10 \mathrm{E}+12$ \\
\hline 11 & & $19 \mathrm{UT}$ & $1.64 \mathrm{E}+11$ & 3.633476 & 5.5 & $3.75 \mathrm{E}+11$ \\
\hline 13 & & $23 \mathrm{UT}$ & $2.12 \mathrm{E}+11$ & 4.13675 & 5.2 & $3.35 \mathrm{E}+11$ \\
\hline 14 & 27-Sep-2017 & $07 \mathrm{UT}$ & $1.04 \mathrm{E}+12$ & 9.173397 & 13.3 & $2.19 \mathrm{E}+12$ \\
\hline 15 & & $10 \mathrm{UT}$ & $1.01 \mathrm{E}+12$ & 9.016292 & 12.7 & $2.00 \mathrm{E}+12$ \\
\hline 16 & & $22 \mathrm{UT}$ & $1.36 \mathrm{E}+11$ & 3.311196 & 2.88 & $1.03 \mathrm{E}+11$ \\
\hline 17 & 28-Sep-2017 & $07 \mathrm{UT}$ & $1.05 \mathrm{E}+12$ & 9.200719 & 14.2 & $2.50 \mathrm{E}+12$ \\
\hline 18 & & $08 \mathrm{UT}$ & $1.04 \mathrm{E}+12$ & 9.150291 & 15 & $2.79 \mathrm{E}+12$ \\
\hline 19 & & $10 \mathrm{UT}$ & $1.06 \mathrm{E}+12$ & 9.2671 & 13.4 & $2.23 \mathrm{E}+12$ \\
\hline 20 & & $22 \mathrm{UT}$ & $1.66 \mathrm{E}+11$ & 3.660848 & 2.17 & $5.84 \mathrm{E}+10$ \\
\hline 21 & 29-Sep-2017 & $07 \mathrm{UT}$ & $1.06 \mathrm{E}+12$ & 9.227304 & 13.3 & $2.19 \mathrm{E}+12$ \\
\hline 22 & & $09 \mathrm{UT}$ & $9.80 \mathrm{E}+11$ & 8.891143 & 14.4 & $2.57 \mathrm{E}+12$ \\
\hline 23 & & $10 \mathrm{UT}$ & $1.05 \mathrm{E}+12$ & 9.223511 & 13.6 & $2.29 \mathrm{E}+12$ \\
\hline 24 & & $20 \mathrm{UT}$ & $8.73 \mathrm{E}+10$ & 2.653589 & 3.22 & $1.29 \mathrm{E}+11$ \\
\hline
\end{tabular}



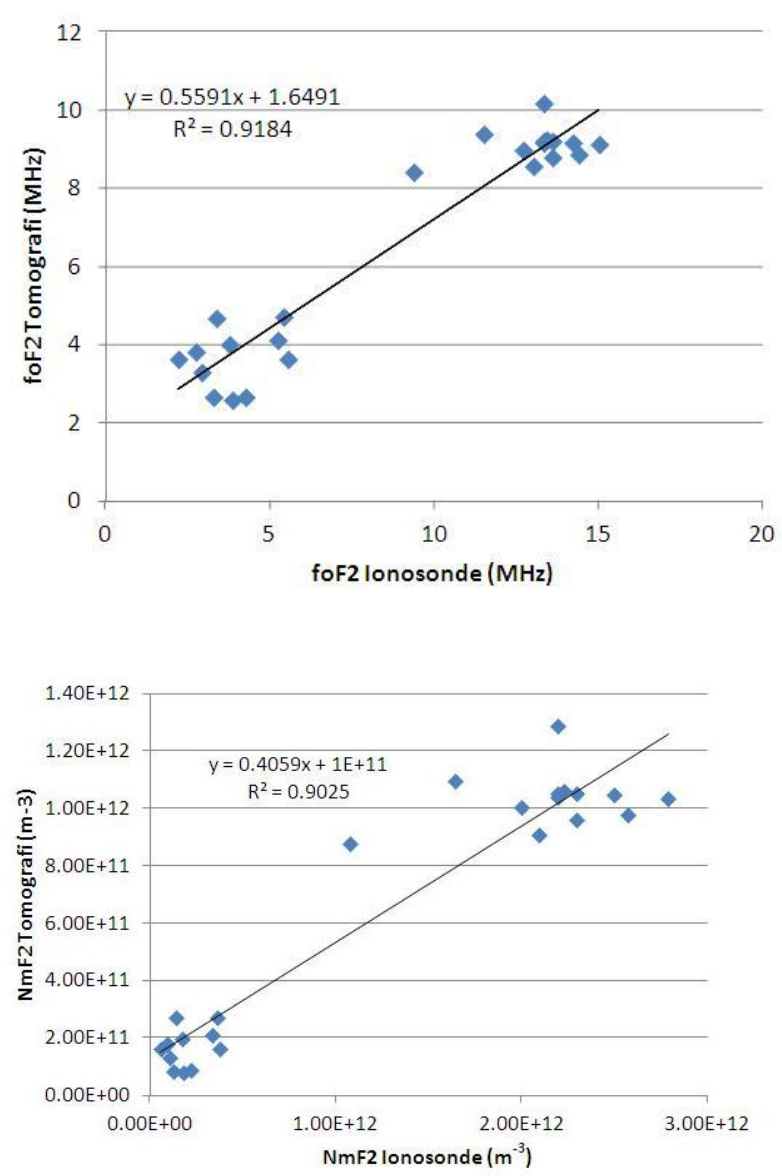

Figure 9. Comparison with the ionosonde observation, with foF2 (left), and with $\mathrm{NmF} 2$ (right).

For validation of the tomography results, correlation of foF 2 from the tomography with foF2 obtained from ionosonde observation is conducted and the results are shown in Table 1. Total of 25 sets tomography has been compared to ionosonde observation.

When taking comparison for foF2 value of the ionosonde observation, the quality of the tomography is good and met a compatibility level through correlation coefficient of 0,9184 and bias frequency $1,6491 \mathrm{MHz}$ as shown in Figure 9 (left). Comparison between the maximum electron density value of $\mathrm{NmF} 2$ of the tomography and of taking from ionosonde gives the regression equation of $y=0.4059 x+(1 x$ 1011) with the correlation coefficient of 0.9025 as shown in Figure 9. (right).

The ionospheric tomography method utilized in this work can be relied upon to monitor the ionosphere, especially for areas that cannot be covered by ionosphere observations. Enhancement of resolution in altitudes scales up to $25 \mathrm{~km}$ can increase the results of ionospheric tomography. Comparison with foF2 value of ionosonde observation met a compatibility through correlation coefficient of 0.9184 , and a bias frequency of $1.6491 \mathrm{MHz}$, while with $\mathrm{NmF} 2$ gives correlation coefficient of 0.9025 . Although this results are better than the previous work, this result needs to be improved with an increase resolution in horizontal scales in order to get Good tomography and lower value of bias frequency.

\section{CONCLUSIONS}

Tomograms resulting from tomographic reconstruction of ionospheric electron density from previous work are shown in Figure 5. The vertical axis is the altitude of the ionosphere in kilometers $(\mathrm{km})$, and the horizontal axis is the position of the geographical latitude.

The results of ionospheric tomography reconstruction from previous work provided an overview of the ionospheric vertical distribution over West Java along the longitude of $108^{\circ} \mathrm{E}$. In general, it can be seen the range of electron density values at night between $0.5-2 \times 1011$ electrons $/ \mathrm{m}^{3}$, in the range $2-4 \times$ 1011 electrons $/ \mathrm{m}^{3}$ during the midday, and in the range of $2.5-5.5 \times 1011$ electrons $/ \mathrm{m}^{3}$ and more during the day. Following the procedure of tomography as mentioned on the previous work, the computation of the tomography is again carried out.

Taking comparison for foF2 value of the ionosonde observation, the quality of the tomography is good and met a compatibility level through correlation coefficient of 0,9184 and bias frequency $1,6491 \mathrm{MHz}$ as shown in Figure 9 (left). Comparison between the maximum electron density value of $\mathrm{NmF} 2$ of the tomography and of taking from ionosonde gives the regression equation of $y=0.4059 x+(1 \times 1011)$ with the correlation coefficient of 0.9025 as shown in Figure 9.

The ionospheric tomography utilized this work can be relied upon to monitor the ionosphere, especially for areas that cannot be covered by ionosphere observations. Comparison with foF2 value of ionosonde observation met a compatibility through correlation coefficient of 0.9184 , and a bias frequency of $1.6491 \mathrm{MHz}$, while with $\mathrm{NmF} 2$ gives correlation coefficient of 0.9025 . Although this results are better than the previous work, this result needs to be improved with an increase resolution in horizontal scales in order to get Good tomography and lower value of bias frequency.

\section{ACKNOWLEDGEMENTS}

We thank to all members in GRBR stasions around Indonesia, and when conducting campaign observation during 2016 and 2017. We also thank to Space Science Center of National Institute of Aeonautics and Space (LAPAN) for supporting buddget to conduct this research since the beginning.

\section{REFERENCES}

Austen, J. R., S. J. Franke, C. H. Liu, K. C. Yeh, 1986. Application of computerized tomography techniques to ionospheric reaserch, in Tauriannen A., (Editor), Proceeding of URSI and COSPAR 
Int. Beacon Satellite Symposium, Part. 1, University of Oufu, Finlandia, pp. 23-35.

Austen, J. R., S. J. Franke, C. H. Liu, K. C. Yeh, 1988. Ionospheric imaging using computerized tomography, Radio Science 23, pp. 299-307.

Batubara, M., T. Manik, M. Lathif, and P. Sitompul, 2016. Iterative Algorithm for Construction of Electron Density Mapping based on Beacon Satellite Observation Data, Proceedings of ISAST IV, 2016, Lombok, September, 20-22, 2016.

Compston, D., International Reference Ionosphere (IRI) Model version 1.14.0.0 (www.mathworks.com)

Leitinger, R. G. Schmid and A. Tauriainen, 1975. An evaluation method combining the differential Doppler measurement from two stations that enables the calculation of electron content of the ionosphere, J. Geophys., 40, 201-213.

Manik, T., dan M. Lathif, 2011. Jaringan GRBR Indonesia, Proc. SNSAA 2011, Serpong, 22-23 November 2011.

Manik, T., M. Batubara M. Lathif, M. Yamamoto, 2017. Rekonstruksi Tomografi Kerapatan Ionosfer Berbasis Pengamatan GRBR di Indonesia, Seminar Nasional Sains Antariksa (SNSA) 2017, Prosiding Seminar Nasional Sains Antariksa 2017, Bandung, 22 November 2017.
Manik, T., A. Purwono, M. Lathif, M. Batubara, M. Yamamoto, 2018. The use of beacon TEC data from Campaign-based observation for ionosphere tomography over West Java Indonesia, Jurnal Sains Dirgantara. DOI: http://dx.doi.org/10.30536/j.jsd.2018.v15.a2896

Thampi, Smitha V., Sudha Ravindran, C.V. Devasia, P. Sreelatha, T. K. Pant, R. Sridharan, Venkat Ratnam, A.D. Sharma, C. Raghava Reddi, J. Jose, and J.H. Sastry, 2007. Coherent radio experiment (CRABEX) for tomographic imaging of the equatorial ionosphere in the Indian longitudes: Preliminary results, Adv. Space Res., 40, 436-441.

Thampi, Smitha V. and Mamoru. Yamamoto, 2010. First result from the ionospheric tomography experiment using beacon TEC data obtained by means of a network along a longitude of $1360 \mathrm{E}$ over JAPAN, Earth Planets Space, Vol. 62 (No. 3), pp. 359-364.

Vierinen, J., J. Norberg, M.S. Lehtinen, O. Amm, L. Roininen, A. Vaananen, P.J. Erickson, D. McKay-Bukowski, 2014. Beacon satellite receiver for ionospheric tomography, Radio Science doi. 10.1002/2014RS005434.

Yamamoto, M., 2008. Digital Beacon Receiver For Ionospheric TEC Measurement, Earth Planets Space, 60 e21-e24. 
THIIS PA GE INTENTIONALLY LEFT BLANK 